\title{
Morbi Infectious Mortality of Diabetics Hospitalized at the Medical Clinic of Abass Ndao Health Center
}

\author{
Djiby Sow ${ }^{1,2}$, Demba Diédhiou¹, Ibrahima Mané Diallo1, Michel Assane Ndour1, Mahecor Diouf ${ }^{1}$, \\ Marie Ka-Cissé1, Anna Sarr ${ }^{1}$, Maimouna Ndour-Mbaye ${ }^{1}$ \\ ${ }^{1}$ Clinique Médicale II, Centre Hospitalier Abass Ndao (UCAD), Dakar, Senegal \\ ${ }^{2}$ Medical Clinic of Abass Ndao Health Center, Cheikh Anta Diop University, Dakar, Senegal \\ Email: drdjibysow@gmail.com
}

How to cite this paper: Sow, D., Diédhiou, D., Diallo, I.M., Ndour, M.A., Diouf, M., Ka-Cissé, M., Sarr, A. and Ndour-Mbaye, M. (2018) Morbi Infectious Mortality of Diabetics Hospitalized at the Medical Clinic of Abass Ndao Health Center. Open Journal of Endocrine and Metabolic Diseases, 8, 1-8. https://doi.org/10.4236/ojemd.2018.81001

Received: November 9, 2017

Accepted: December 30, 2017

Published: January 2, 2018

Copyright $\odot 2018$ by authors and Scientific Research Publishing Inc. This work is licensed under the Creative Commons Attribution International License (CC BY 4.0).

http://creativecommons.org/licenses/by/4.0/

\begin{abstract}
Introduction: Diabetes is a public health problem and is exposed to some complications, particularly infectious. The work on this entity remains segmentary in Africa. The objective was to describe the morbi infectious mortality of the diabetics at the Medical Clinic II of Abass Ndao Health Center of Dakar. Patients and Methods: This was a cross-sectional, descriptive and analytical study conducted from 01 January 2016 to 31 December 2016. It covered patients with diabetes hospitalized during the study period. Epidemiological data and infectious diseases were evaluated. Results: During the study period, 346 diabetics have respected the inclusion criteria. These were 165 men (47.68\%), a sex ratio of 0.91 . The mean age was 56.17 years. The age group of [60 - 69 years] accounted for $31.5 \%$ and $95.6 \%$ of the patients came from the Dakar region. The average age of diabetes was 10.31. Diabetes had been evolving for less than 5 years in $25.15 \%$ of patients and inaugural in $11.46 \%$. About $82.36 \%$ of our patients had type 2 diabetes. The acute complications of diabetes were ketoacidosis (51.89\%), hyperosmolar hyperglycemia (0.58\%), and hypoglycemia (1.45\%). The mean infections were the skin and soft tissues (54.91\%), urogenital infections (16.18\%), respiratory infections (14.45\%), malaria (3.46), infections of the skin and soft tissues were dominated by the diabetic foot $(41.90 \%)$. The 125 non-diabetic patients developed 38 infectious pathologies, the main ones being respiratory infections $(24.32 \%)$, infections of the skin and soft parts (24.32\%). HIV infection was observed in $0.28 \%$ of diabetics and $8.10 \%$ of non-diabetic patients. 93 patients died (15.70\%). Fifty-one of them died of infectious diseases (54.8\%), 42 non-infectious diseases (45.16\%), and subjects aged over 60 years, representing $72.54 \%$. The means of consultation was 30 days. The highest rates of lethality were diabetes $(37.41 \%)$, acute gastroenteritis (17.64\%), and acute pyelonephritis (12.5\%). The lethality rates of indetermi-
\end{abstract}


nate infections and malaria were $10 \%$ and $8.33 \%$, respectively. Conclusion: Infection is a significant complication in diabetics not neglectable to diabetes. These discovery patterns call for more early diagnosis and appropriate management to reduce the mortality of diabetics.

\section{Keywords}

Morbimortality, Diabetes, Infection, Senegal

\section{Introduction}

Diabetes is a public health problem due to medical, social and financial implications [1].

The International Diabetes Federation (IDF) 2015 estimates report a prevalence of $8.8 \%$. Prevalence in sub-Saharan Africa increased from $4.8 \%$ to $5.7 \%$ [2]. In Senegal, prevalence data remains approximate. According to IDF's 2015 estimates, 3.24\% of the Senegalese population would be diabetic [2] [3]. As a result, diabetes leads to chronic complications and increases susceptibility to infections through reduced lymphocyte response [4]. According to the World Health Organization, infectious diseases are the leading cause of morbidity and mortality in developing countries in general and Africa in particular [5]. The few existing data in the field relate to epidemiological, clinical and evolutionary aspects. This study had motivated this study with the objective of specifying the proportion of infectious diseases and identifying the main causes of death in the context of these conditions in the internal medicine department of the Abass Ndao Health Center in Dakar.

\section{Materials and Methods}

It's about a descriptive cross-sectional study carried out at the internal medicine department of the Abass Ndao Health Center in Dakar from 1 January 2016 to 31 December 2016. It focuses on diabetic patients of all types aged less than 10 years hospitalized in the department of internal medicine (department affiliated to the national reference center in the management of diabetes and metabolic diseases since 1960). Non-diabetic subjects hospitalized during the study period and diabetic subjects with incomplete records were not included. A pre-established questionnaire or inquiry had been used to collect data relevant to the evaluation. Data collection was carried out on patient records and the hospitalization register. For this survey, we selected the following variables:

- Socio-demographic characteristics: sex, age grouped by age and occupation, provenance;

- The study of diabetes mellitus: age, type of diabetes, nature of ongoing treatments, cardiovascular risk factors and chronic complications of associated diabetes, level of glycemic control using capillary blood glucose;

- Clinical characteristics: diagnosis, consultation time, duration hospitaliza- 
tion and the evolution of patients. The data for the clinics that contributed to the diagnosis and management of the patients, and resulting from the feasible examinations at the Abass Ndao Health Center, were: 1) thick blood glucose and blood smear for malaria, 2) cytobacteriological and mycology of the CSF for meningitis, 3) the search for acid-alcohol-resistant bacilli (BAAR) on sputum and gastric tubing liquid for tuberculosis, 4) HIV serology, 5) chest X-ray, 6) other biological analyzes (blood cultures, coprocultures, ECBU, transaminases, $\mathrm{HBsAg}$ and $\mathrm{AgHBe}, \mathrm{AcHBc}$ ).

The statistical analysis was carried out by the Epi Info 6.0 software.

\section{Results}

\section{1) Sociodemographic characteristics}

During the study period, we have 383 patients. Among these patients, there were 346 diabetics who met the inclusion criteria $(90.33 \%)$ and 37 patients without diabetes $(9.66 \%)$. There were 165 men $(47.68 \%)$ and 181 women $(52.31 \%)$, a sex ratio of 0.91 . The mean age was 56.17 years with extremes of 15 to 90 years. The age group of 60 years and 69 years represents 109 cases (31.5\%) of the hospitalized patients. In our study, $95.6 \%$ of the patients came from the Dakar region. The Table 1 shows the socio-demographic characteristics of the subjects.

\section{2) Diabetes study}

The mean age of diabetes was 10.31 years with extremes of 0 to 38 years. Diabetes evolved for less than 5 years in $25.15 \%$ of patients and inaugural in $11.46 \%$. Approximately $82.36 \%$ of our patients had type 2 diabetes. The treatment was essentially insulin in $48.71 \%$ and oral anti-diabetics in $42.30 \%$. The acute complications of diabetes were ketoacidosis (51.89\%), hyperosmolar hyperglycemia $(0.58 \%)$, hypoglycemia $(1.45 \%)$, electrocardiographic signs suggestive of coronary artery disease (30.6\%). Mean fasting blood glucose was $3 \mathrm{~g} / \mathrm{l}$ with extremes of 0.4 and HI. Only 63 patients had blood glucose (<2 g.l).

\section{3) Pathologies observed}

The 717 patients presented with pathologies, including 383 infectious medical (53.41\%), 324 non-infectious (45.18\%) and 10 surgical (1.39) Among 717 patients, 592 were diabetic, a prevalence of $82.56 \%$ and 125 patients were non-diabetic i.e. $17.43 \%$. In 592 diabetic patients, 348 infectious diseases were observed, the main ones being skin and soft tissue infections (54.91\%), urogenital infections (16.18\%), respiratory infections (14.45\%), malaria (3.46\%), digestive infections (6.93\%) and oral infections $(5.49 \%)$ (Table 1). Skin infections were dominated by diabetic foot $\%$ and abscesses $(7.22 \%)$. Tuberculosis and pneumonia represent respectively $(2.60 \%)$ and $(8.67 \%)$ respiratory infections. The 125 non-diabetic patients developed 38 infectious pathologies, the main ones being respiratory infections (24.32\%), skin and soft tissue infections (24.32\%), digestive infections (21.62\%) and malaria (13.51\%) (Table 1). Infection was observed in $0.28 \%$ of diabetics and $8.10 \%$ of non-diabetic subjects.

Table 2 shows the distribution of patients according to the infectious pathologies observed. 
Table 1. Distribution of patients by sociodemographic characteristics.

\begin{tabular}{cc}
\hline \multicolumn{2}{c}{ Characteristics of Patients in Inclusion $(\mathbf{n}=346)$} \\
Average Age & 56.2 years \\
Age $\geq$ 60 Years & $49.1 \%$ \\
Women & $52.3 \%$ \\
Sex Ratio (M:F.) & 0.9 \\
Diabetes Type 2 & $82.4 \%$ \\
Average Age of Diabetes & 10.3 years \\
Duration of Hospitalization Average & 10.4 days \\
Inaugural Diabetes & $11.5 \%$ \\
(OAD) Oral Anti Diabetic Treatment & $48.3 \%$ \\
Glycemia > 2 mg/dl & $76.4 \%$ \\
Acidocétosis and Hyperosmolarity & $51.5 \%$ \\
Dead & $14.73 \%$ \\
Average Time for Consultation & 24.1 days \\
Deadline for Consultation > 10 days & $48.7 \%$ \\
\hline
\end{tabular}

Table 2. Distribution of patients by infectious diseases observed infectious diseases.

\begin{tabular}{ccc}
\hline Infectious Pathology & Number $(\mathbf{n}=\mathbf{3 4 6})$ & Frequency (\%) \\
\hline Respiratory disease & 50 & 14.5 \\
Common pneumonia & 35 & 10.1 \\
Tuberculosis & 9 & 2.6 \\
Infectious ORL & 6 & 1.7 \\
Skin and soft part & 190 & 54.9 \\
Foot and hand infection & 156 & 45.1 \\
Abscess and myositis & 29 & 8.4 \\
Other & 5 & 1.4 \\
Urogenitals infections & 56 & 16.2 \\
Pyelonéphrit acute & 8 & 2.3 \\
Prostatis & 5 & 1.4 \\
Low urogenitals infections & 43 & 12.4 \\
Digestives infections & 43 & 12.4 \\
Gastro enteritis acute & 17 & 4.9 \\
Abscess of liver & 4 & 1.2 \\
Acute cholecystitis & 1 & 0.3 \\
Candidiasis buccal & 2 & 0.6 \\
Oral infections dental & 19 & 5.5 \\
Other infections & 41 & 11.8 \\
Articulations acute & 6 & 1.7 \\
Méningitis & 1 & 0.3 \\
Ganglionic tuberculosis & 1 & 0.3 \\
Malaria & 12 & 3.5 \\
Undetermined infections & 20 & 5.8 \\
HIV & 1 & 0.3 \\
\hline
\end{tabular}

\section{4) Causes of death}

Among the 592 hospitalized patients with diabetes, 93 died (15.70\%). Fifty-one of them are infectious diseases (54.8\%), 42 non-infectious diseases (45.16\%). Patients over 60 years of age and $725.4 \%$ and mean consultation time were 30 days. The causes of death of the 51 patients who died of infectious diseases are mainly 
dominated by diabetic foot 36 cases, pneumonia 5 cases and acute gastroenteritis 3 cases (Table 2); the prevalence of malaria was $1.96 \%$ in these subjects was $74.3 \%$. The mortality rate for infectious diseases was $14.73 \%$. In the non-diabetic patients, five deaths with HIV prevalence were observed in $20 \%$ of the patients. Mortality rates were highest in the diabetic foot (37.41\%), acute gastroenteritis (17.64\%) and acute pyelonephritis (12.5\%). The mortality rate for indeterminate infections and malaria was $10 \%$ and $8.33 \%$, respectively. Table 3 shows the distribution of patients according to the clinical characteristics of the living and deceased patients.

\section{Discussion}

Infectious medical pathologies were the first cause of morbid mortality in the internal medicine department of the Abass Ndao Health Center. Indeed, there are $53.41 \%$ of the pathologies responsible for hospitalizations and $57.14 \%$ of the causes of death in the service during the period of study. This retrospective study, which may be underestimating the reality of infectious pathology in the internal medicine department due to non-analyzed records for missing data, is the first of its kind carried out in our department. The prevalence of infection (58.78\%) was as high in hospitalized patients with diabetes as in patients who died. In Africa, infections, as the main causes of decompensation of diabetes, interrupted therapeutic [6]. This is in agreement with other authors. In Senegal, Sarr [7] found $78 \%$ of concomitant infections and in Algeria Boutabia [8] found a predominance of infectious factors in $51.7 \%$ of cases in his series. Thus, the causes of morbidity were dominated by infections (16.98\%), respiratory infections (14.45\%), malaria (3.46\%), digestive infections (6.93\%), skin infections and soft tissues and oral infections (5.49\%). The infectious pathologies remain the same with a variable distribution

Table 3. Distribution of patients by clinical characteristics of patients and deceased patients.

\begin{tabular}{ccccc}
\hline Clinical characteristic of patients & Alive (295) & Frequency \% & Deceased (51) & Frequency \% \\
\hline Average age & 54.60 & 65.23 & 72.54 \\
$>$ 60 years & 133 & 45.08 & 37 & \\
Average consultation time & 22.95 & 30.91 & 61.53 \\
Capillary blood & 3.07 & 2.55 & \\
Glucose $>$ 2 mg/dl & 174 & 24 & \\
Diabetes progression time & 10.32 & 10.26 & 9.80 \\
Hospitalization time & & & 78.43 \\
Average & 10.87 & 7.84 & 1.96 \\
Infectious pathologies & & & 5.88 \\
Respiratory & 45 & 5 & 0 \\
Skin and soft tissues & 150 & 40 & 7.84 \\
Urogenitals & 9 & 1 & 0 \\
Bone infection & 3 & 3 & 3.92 \\
Neuromeningees & 1 & 0 & 1.96 \\
Digestives & 18 & 4 & 0 \\
Ganglionic & 1 & 0 & 2 & \\
Undetermined & 18 & 1 & \\
Parasitic & 1 & & \\
Retro virology & & & \\
\hline
\end{tabular}


of the reports in the literature. Our study differs from that of Sarr [7] and Umpierrez [9] found a predominance of urogenital and bronchopulmonary infections. This is due to the fact that there is a proximity to the podiatry unit that refers to unbalanced patients with skin infections. Diabetics are more prone to infections of the skin and soft tissues. These infections may occur during the course of the disease or may be the first sign of diabetes presentation [10] and may be more severe in these populations [11]. Skin and soft tissue infections are the leading cause of morbidity in our series. Skin infections were dominated by the diabetic foot (41.90\%). The latter arrives in hospital at a stage of gravity which can lead to amputation. This requires effective therapeutic education to improve the amputation rate. The average age of our patients ( 56.17 years) was similar to that found by the Masoodi team (50.5 \pm 13.3 years) [12]. The age range of [60 - 69] represents $31.5 \%$. However, the male predominance with a sex ratio of 0.91 found in our study $(47.68 \%)$ is not shared with the literature [12] [13]. Infection is one of the complications revealing diabetes as in Uganda [13]. In our study it is in $11.46 \%$. Ignorance due to lack of information on routine diabetes screening and neglect of diabetes symptoms would be the cause of this delay in diagnosis [14]. The average diabetes seniority was 10.31 years higher to that reported by Raherison [15] in Madagascar (6.69 years) and Masoodi (6.6 \pm 5.6 years) [12]. The infection leads to an imbalance of diabetes [16]. A hyperglycemia greater than $2 \mathrm{~g} / \mathrm{l}$ is found in our study in $76.39 \%$. The acute complications of diabetes were ketoacidosis $(51.89 \%)$, hyperosmolar hyperglycemia $(0.58 \%)$, and hypoglycemia (1.45\%). Respiratory infections are represented in our study (14.45\%). This rate is lower than in Burkina Faso [17] and Madagascar [15] with $47 \%$ and $40.74 \%$, respectively. Tuberculosis was a common lung infection in our patients. There does not appear to be a prevalence of tuberculosis in diabetic patients in developed countries. However, in the developing regions of the world, tuberculosis continues to be a major challenge. We have already documented tuberculosis as a major lung infection in diabetic patients [18]. It has been suggested that the recrudescence of tuberculosis may explain a high-level infection in diabetic patients in developing countries. There is also evidence of an increase in the rate of tuberculosis in diabetic patients and new patients in tuberculosis patients in Africa [19]. Urinary tract is the most prevalent in the prevalence of infection among diabetic patients [20]. It represents a rate of $16.18 \%$ in our study. High rates were found in the Sharikstudy of $28.42 \%$ [21]. This finding should prompt us to ask for more explorations of urinary tract biology because these infections can most often be asymptomatic. HIV infection was observed in $0.28 \%$ of diabetics and $8.10 \%$ of non-diabetic subjects. This low rate is explained by a demand for retroviral serology in our patients. Indeed, immunodeficiency syndrome is a disease characterized by clinical polymorphism. Hence, it is necessary to think about and carry out HIV tests. We have found a mortality rate similar to that reported by Shah, et al. (15\%) [22] and lower by that of Esper, et al. (18.5\%) [23]. Subjects aged over 60 years were strongly represented $(72.54 \%)$. This is probably due to a delay in taking care of us. The average time for consultation was 30 days. Mortality rates 
were highest (37.41\%), acute gastroenteritis (17.64\%). The mortality rate of undetermined infections and malaria was $10 \%$ and $8.33 \%$, respectively. The mean hospital stay of our patients was between those reported by the Mokhtar team (10 days) [24] and the team of Rachdi (20 days) [25]. Infections in diabetics always increase economic and hospital costs by prolonging the hospital stay.

\section{References}

[1] Diop, S.N. and Diédhiou, D. (2015) Diabetes Mellitus in Sub-Saharan Africa: Epidemiological and Socio-Economic Aspects. Medicine of Metabolic Diseases, 9, 123-129.

[2] International Diabetes Federation (IDF) (2017) IDF Diabetes Atlas. 8th Edition, International Diabetes Federation, Brussels. http://www.diabetesatlas.org/resources/2017-atlas.html

[3] Mbaye, N.M., et al. (2011) Epidemiological Aspects of Diabetes in Senegal: Results of a Survey of Cardiovascular Risk Factors in the City of Saint-Louis. Medicine of Metabolic Diseases, 5, 659-664.

[4] Muller, L.M., Gorter, K.J., Hak, E., Goudzwaard, W.L., Schellevis, F.G., Hoepelman, A.I., et al. (2005) Increased Risk of Common Infections in Patients with Type 1 or Type 2 Diabetes. Clinical Infectious Diseases, 41, 281-288. https://doi.org/10.1086/431587

[5] WHO (2002) World Health Report 2002: Reducing Risks and Promoting Healthy Lives. WHO, Geneva.

[6] Kakoma, P.K., Kadiebwe, D.M., Kayembe, A.M., Makonga, P.K., Bugeme, M. and Mukuku, O. (2014) Diabetic Ketoacidosis in Adults in Hospital Sendwe Lubumbashi: About 51 Cases. Pan African Medical Journal, 17, 324.

[7] Sarr, A. (2011) Ketoacidosis in the Diabetic Type 1 Patient: About 73 Cases Collected in Dakar. Medical Mali, $26 \mathrm{p}$.

[8] Boutabia, W.A. (2008) Diabetic Ketoacidosis in Children: Experience of the Annaba University Hospital. Archives of Pediatrics, 15, 951.

https://doi.org/10.1016/S0929-693X(08)72156-0

[9] Umpierrez, G.E. and Kitabchi, A.E. (2003) Diabetic Ketoacidosis: Risk Factors and Management Strategies. Treatments in Endocrinology, 2, 95-108. https://doi.org/10.2165/00024677-200302020-00003

[10] Lipsky, B.A., Tabak, J.P., Johannes, R.S., Vo, L., Hyde, L. and Weigelt, J. (2010) Skin and Soft Tissue Infections in Hospitalized Diabetic Patients: Culture Isolates and Risk Factors Associated with Mortality, Duration of Stay and Cost. Diabetologia, 53, 914-923. https://doi.org/10.1007/s00125-010-1672-5

[11] Peleg, A.Y., Weerarathna, T., McCarthy, J.S. and Davis, T.M. (2007) Common Infections in Diabetes: Pathogenesis, Management and Relationship with Glycemic Control. Diabetes/Metabolism Research and Reviews, 23, 3-13. https://doi.org/10.1002/dmrr.682

[12] Masoodi, S.R., et al. (2007) Model of Infections in Patients with Diabetes Mellitus. Data a Tertiary Care Medical Center in the Indian Subcontinent. Diabetes/Metabolism Research and Reviews, 1, 91-95.

[13] Nambuya, A.P., Otim, M.A., Whitehead, H., et al. (1996) Presentation of Newly Diagnosed Diabetic Patients in Uganda. Quarterly Journal of Medicine, 89, 705-711. https://doi.org/10.1093/qjmed/89.9.705

[14] Akossou, S.Y., James, Y.E., Tetekpor, S., et al. (2003) Management of the Diabetic 
Foot at Lomé Tokoin University Hospital. Louvain Médical, 122, 272-280.

[15] Raherison, R.E. (2015) Community Infections in Diabetics Malgaches Hospitalized at Joseph Raseta Hospital in Befelatanana, Antananarivo, Madagascar. La Revue Médicale de Madagascar, 5, 577-581.

[16] Rayfield, E.J., Ault, M.J., Keusch, G.T., et al. (1982) Infection and Diabetes: The Case of Blood Glucose Control. American Journal of Medicine, 72, 439-450. https://doi.org/10.1016/0002-9343(82)90511-3

[17] Ouedraogo, M., Ouedraogo, S.M., Ouedraogo, A.S., et al. (2001) Place of Respiratory Complications in Acute Complications of Diabetes Mellitus at the YalgadoOuedraogo National Hospital. Medecine d' Afrique Noire, 48, 253-256.

[18] Zargar, A.H., Masoodi, S.R., Laway, B.A. and Akhtar, M.A. (1994) Incidence and Pattern of Infections in Diabetes Mellitus. International Journal of Diabetes in Developing Countries, 14, 82-84.

[19] Mugusi, F., Swai, A.B., Alberti, K.G.G.M. and McLarty, D.G. (1990) Increased Prevalence of Diabetes Mellitus in Patients with Pulmonary Tuberculosis in Tanzania. Tubercle, 71, 270-276. https://doi.org/10.1016/0041-3879(90)90040-F

[20] MacFarlane, I.A., Brown, R.M., Symth, R.W., Burdon, D.W. and FitzGerald, M.G. (1986) Bacteremia in Diabetes. Journal of Infection, 12, 213-219. https://doi.org/10.1016/S0163-4453(86)94112-5

[21] Shariq, R. (2007) Pattern of Infections in Patients with Diabetes Mellitus-Data from a Tertiary Care Medical Centre in Indian Sub-Continent Diabetes \& Metabolic Syndrome. Clinical Research \& Reviews, 1, 91-95.

[22] Shah, B.R. and Hux, J.E. (2003) Quantifying the Risk of Infectious Diseases for People with Diabetes. Diabetes Care, 26, 510-513.

https://doi.org/10.2337/diacare.26.2.510

[23] Esper, A.M., Moss, M., Martin, G.S., et al. (2009) The Effect of Diabetes Mellitus on Organ Dysfunction with Sepsis: An Epidemiological Study. Critical Care, 13, 18. https://doi.org/10.1186/cc7717

[24] Mokhtar, A., Zoukar, O., Khochtali, I., et al. (2009) Diabète de type 2 et infection. Diabetes \& Metabolism, 35, 54. https://doi.org/10.1016/S1262-3636(09)71911-1

[25] Rachdi, I., Lamloum, M., Ben Ghorbel, I., et al. (2012) Diabetes of the Elderly and Infections. La Revue de Médecine Interne, 33, 190-198. 